\title{
A Study of Central Line Associated Blood Stream Infections among Patients on Hemodialysis before and after Implementation of a Catheter Care Bundle
}

\author{
Marwa Mostafa Shalaby ${ }^{1, *}$, Kareman Ahmed Eshra ${ }^{1}$, \\ Radwa Abd El moteleb Essa ${ }^{1}$, Ghada Mahmoud Alghazaly ${ }^{2}$ \\ ${ }^{1}$ Infection Control Unit, Department of Microbiology and Immunology, Faculty of Medicine, Tanta University, Egypt \\ ${ }^{2}$ Hemodialysis Unit, Department of Internal Medicine, Faculty of Medicine, Tanta University, Egypt
}

Copyright $\mathrm{O} 2018$ by authors, all rights reserved. Authors agree that this article remains permanently open access under the terms of the Creative Commons Attribution License 4.0 International License

\begin{abstract}
Background: Central venous catheters (CVCs) are often used as a vascular access in patients with end stage renal diseases when emergency hemodialysis is required, before maturation of arteriovenous fistula or graft, or when a permanent access becomes non-functioning. The most common complication following insertion of a CVC is infections including exit site infection, tunnel infection, or central line related blood stream infections (CLABSIs). Preventing such complications is crucial in these vulnerable patients and this can be accomplished by strict adherence to infection control guidelines. This study aimed to evaluate the efficacy of implementation of a CVC care bundle composed of best evidence based practices to see whether the rates of CLABSIs rates would decrease. Methods: the study was divided into pre and post intervention phases. The duration of each phase was 6 months during which rates of confirmed CLABSIs per 1000 catheter days as well as the causative microorganisms were recorded. The data were then compared and analyzed to evaluate the intervention. Results: CLABSIs rates decreased from 6.7 in phase 1 to 4.1 in phase 2 . The relative risk reduction was 0.39 . Conclusions: Implementation of bundles for insertion and maintenance of CVCs can help preventing CRBSIs which is very important to improve patient care.
\end{abstract}

Keywords Central Line Associated Blood Stream Infections, CLABSIs, Central Venous Catheter, CVC, Bundle

\section{Introduction}

One of the major health problems in the world is the end-stage renal disease (ESRD) [1]. Vascular access is considered the bridge between the patient and the machine circuit. That is why it is called the "Achilles heel of hemodialysis [2]. The good performance of dialysis vascular access is the main factor that affects the survival and quality of life of patients with ESRD [3]. Arteriovenous fistula (AVF), arteriovenous graft and central venous catheter (CVC) are the main three vascular accesses used in hemodialysis. Usually, CVCs are required in case of emergency hemodialysis, either when a permanent access becomes non-functioning or at the time of initiation of renal replacement therapy [4].

Chronic hemodialysis patients are at high risk to infection especially those with CVCs as patients with catheters have a 2 to 3 folds increased risk of hospitalization for infection and death compared with patients with an AVF or graft [5]. Common infections related to hemodialysis CVC usage include central line associated bloodstream infections (CLABSIs), exit-site infections, and tunnel infections. CLABSIs lead to increased morbidity, hospitalization, and death [6].

CLABSI means the presence of bacteraemia originating from a central line catheter [7]. CLABSI is a common cause of health care associated bacteramia and septicaemia, and it is a major cause of morbidity and mortality. Considering device related infections, CVCs are associated with a greater risk of device related infections compared to any other medical device [8].

In order to cause infections, microorganisms must have an access to the catheter, either through the extra-luminal surface or intra-luminal surface of the catheter, in which they usually form a biofilm. This access occurred at the time of the $\mathrm{CVC}$ insertion through percutaneous route or a few days afterwards, or through catheter hub (and lumen) contamination when the catheter is inserted over a percutaneous guide wire or when it is later manipulated [9]. Hematogenous dissemination of the microorganisms from 
elsewhere and contamination of the infusion liquid are other possible causes of infections [10].

The diagnosis of CLABSI depends on isolation of the same microorganism from the catheter tip and at least one blood culture, with presence of clinical manifestations of infection and no other detectable source of infection [11]. Causative microorganisms that cause $\mathrm{CVC}$ infections are almost bacteria, with a significant percentage of multi-drug resistant bacteria. The Gram-positive cocci are the principle causative bacteria, especially Staphylococcus aureus with great consideration to Methicillin-resistant Staphylococci, coagulase-negative Staphylococci including Methicillin-resistant Staphylococcus epidermidis (MRSE), and Enterococci including Vancomycin-resistant Enterococci (VRE) [12-16].

The ability to Control infection in hemodialysis patients is a challenging task for healthcare staff specially because catheters are often manipulated during hemodialysis session and the hemodialysis patients are immunocompromized [17]. However, with focus on education and strict implementation of the infection prevention and control programs, CLABSI rates could be decreased [18].

\section{Methods}

\section{Study Design}

This study was carried out at Hemodialysis Unit, Internal Medicine department, Faculty of Medicine, Tanta University. The study was designed in 2 phases; phase 1 was in the period from May to October, 2016. Phase 2 was in the period from December to May, 2017. During phase 1, education and training of the health care workers in the unit was done to prepare for implementation of CLABSI prevention bundle (from November, 2016). The care bundle was adopted from center for disease control and prevention $(\mathrm{CDC})$ evidence based practices for insertion and maintenance of CVCs. Throughout the study, the numbers of CLABSIs, the rates of infection were calculated, and causative microorganisms were detected.

\section{Patients}

Inclusion Criteria of the patients were any patient with CVC who developed signs and symptoms suspicious of CLABSI before or during hemodialysis session (core temperature of $>38^{0} \mathrm{C}$ or $<36^{\circ} \mathrm{C}$, tachycardia $>90 / \mathrm{min}$, tachypnea $>20 / \mathrm{min}$, or transient hypotension, chills, malaise, abdominal pain, nausea, vomiting, diarrhea, anxiety, shortness of breath and confusion). Patients were included only if the catheter was in place for $>2$ calendar days on the date of event. Exclusion Criteria were patients taking antibiotic treatment, and patients on hemodialysis with arteriovenous (AV) fistula or any vascular access other than CVC [19].

\section{Microbiological Workup}

\section{Blood Cultures}

Blood samples were collected under complete aseptic conditions from the catheter hub and a peripheral vein. Hubs and circuit ports were first cleansed with alcohol based chlorhexidine. CLABSI was confirmed when the same microorganism was isolated from simultaneous quantitative cultures of blood samples with a ratio of $\geq 3: 1$ (catheter versus peripheral).

\section{Catheter Tips}

If the catheter was removed, distal $5 \mathrm{~cm}$ of catheter segment was cut aseptically, and it was cultured by Maki's standard semi-quantitative method. A colony count of $\geq 15$ was considered significant [20].

Events of CLABSIs were diagnosed based on the definition criteria set by National Healthcare Safety Network of the US Center for Disease Control and Prevention [19].

Identification and antibiotic sensitivity testing of the isolated microorganisms was done using automated vitek2 system (Biomerieux, France) in the Microbiology and Immunology Department, Faculty of Medicine, Tanta University.

\section{Implementation of CLABSI Prevention Bundle}

The bundle was adopted from best evidence-based practices [16] and was implemented from November, 2016. The bundle included:

1. Hand hygiene; surgical hand hygiene either with alcohol-based hand rub or hand wash with antiseptic soap. Hand hygiene should be performed before and after palpating catheter insertion sites as well as before and after inserting, replacing, accessing, repairing, or dressing an intravascular catheter site.

2. Maximal barrier precautions; a mask, a cap, a sterile gown, and sterile gloves were used during insertion. A large (head-to toe) sterile drape over the patient was also used during the placement or exchange of a CVC catheter.

3. Prepare and clean the skin site with an alcoholic chlorhexidine solution containing a concentration of $>0.5$ chlorhexidine and $70 \%$ alcohol before central venous catheter insertion and during dressing changes. If there is a contraindication to chlorhexidine, tincture of iodine, an iodophor, or $70 \%$ alcohol can be used.

4. Optimal site selection; for short term hemodialysis, use internal jugular or less preferable femoral vein.

5. Using either sterile transparent, semipermeable dressing, or gauze to cover the catheter site. 
6. Scrubbing the catheter ports and hub with an appropriate antiseptic.

\section{Statistical Analysis}

Baseline (pre-intervention) and post-intervention rates of CLASBIs in the unit were calculated as the sum of all CLABSIs reported during the study period. Unit level CLABSIs rate was calculated as $\frac{\text { CLABSIs }}{\text { central line days }} \times 1000$ [21]. Compliance to the bundle were measured by the number of patients in the unit with central line for whom elements of the bundle were fulfilled and documented divided by the total number of the unit patients with central line [22]. Data were analyzed using SAS version 9.3 (SAS Institute Inc. 2011. Base SAS ${ }^{\circledR} 9.3$ Procedures Guide. Cary, NC: SAS Institute Inc.).

\section{Results}

During the pre-intervention phase, 19 CLABSI events were recorded in 66 patients in whom 94 CVCs were inserted for 2820 days. CLABSIs rates were 8.5, 6.1, 4.1, 6.7, 7, and 8 during May, June, July, August, September, and October, 2016 respectively. The average rate was 6.7 However, during the post-intervention phase, 13 CLABSI events were recorded in 75 patients in whom 91 CVCs were inserted for 3133 days. CLABSIs rates were 5.8, 4, 6, 3.8, 4.1, and 1.6 during December, 2016, January, February, March, April, and May, 2017 respectively. The average rate was 4.1 (Fig.1). The relative risk reduction was 0.39 after implementation of the bundle.

Figure 2 presents the percentages of compliance of nurses and resident doctors in the unit to the implemented catheter care elements. Compliances to hand hygiene, Maximal barrier precautions, skin anti-sepsis, optimal site selection, sterile dressing use, and scrubbing catheter ports and hub were $92 \%, 73 \%, 100 \%, 87 \%, 100 \%$, and $83 \%$ respectively, while compliance to all bundle elements together was $69 \%$.

During the study period, 37 microorganisms could be isolated from 32 confirmed CLABSIs. The most commonly isolated bacteria were Staphylococcus aureus (35.1\%), followed by Coagulase Negative Staphylococci (29.7\%), Pseudomonas aeruginosa (18.9\%), Klebsiella pneumonia (10.9\%), Enterobacter cloacae $(2.7 \%)$, and Acinetobacter baumannii (2.7\%). Eighty-one percent of the isolated organisms were multidrug resistant (MDROs) (Fig.3).

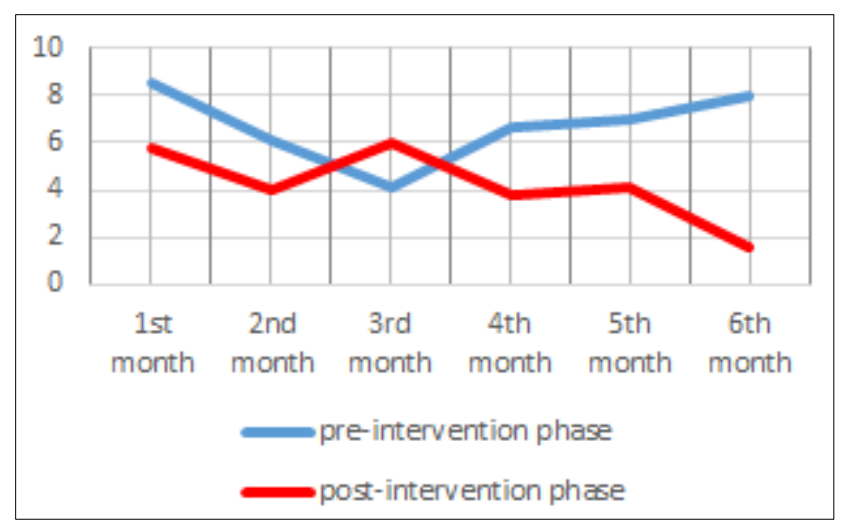

Figure 1. Comparison of CLABSIs rates (per 1000 catheter days) in pre and post-intervention phases of the study

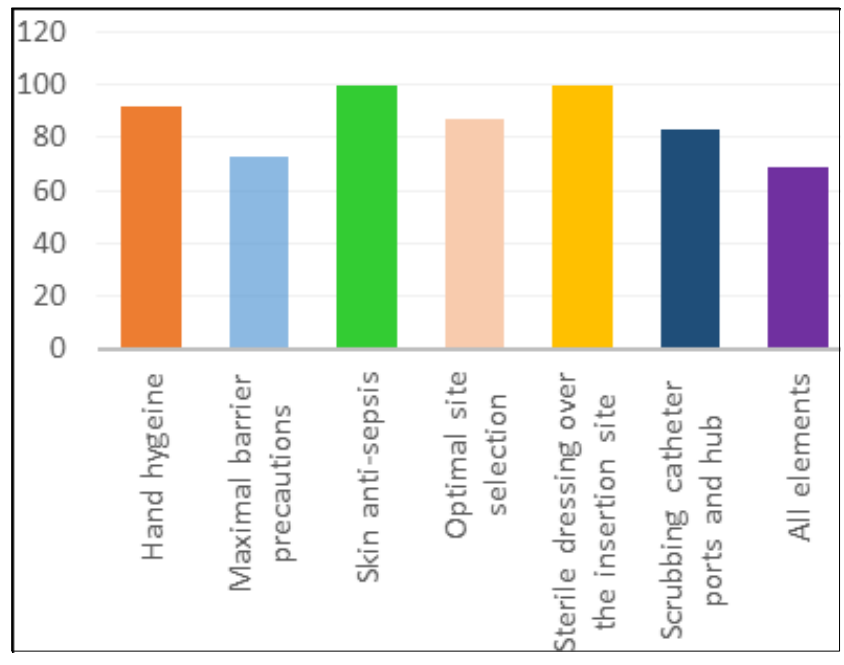

Figure 2. Compliance to the bundle elements.

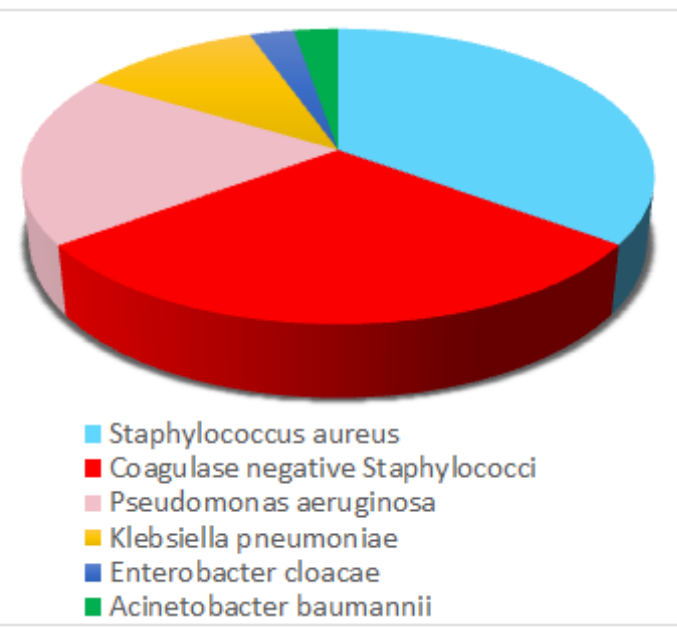

Figure 3. Percentage distribution of isolated microorganisms 
Table 1. Numbers and rates of CLABSIs in pre and post-intervention phases

\begin{tabular}{|c|c|c|}
\hline & $\begin{array}{c}\text { Pre-intervention } \\
\text { phase }\end{array}$ & $\begin{array}{c}\text { Post-intervention } \\
\text { phase }\end{array}$ \\
\hline Total catheter days & 2820 & 3133 \\
\hline Confirmed CLBSIs & 19 & 13 \\
\hline $\begin{array}{c}\text { CLBSIs/1000 catheter } \\
\text { days }\end{array}$ & 6.7 & 4.1 \\
\hline
\end{tabular}

\section{Discussion}

This study demonstrated that the application of CVC care bundle at a hemodialysis unit in Tanta university hospitals was able to reduce the incidence of CLABSIs. CLABSI rate per 1000 catheter days has been decreased from 6.7 in the pre-intervention phase to 4.1 in the post-intervention phase with a relative reduction risk of 0.39 . Although the reduction was expected to be higher, but we could state that with close adherence to the bundle, a further reduction could be achieved in the next months. Many authors reported that CLABSIs can be effectively controlled by applying a multidisciplinary infection control process. Despite the fact that the bundle components in each study may not be identical, these different bundles reduced the rates of infection through their implementation [23-29].

The rates of CLABSIs per 1000 catheter-days in phase 1 (pre-intervention) of the present study were closely related to those mentioned by Guerin et al, 2010 [30] who reported a pre-intervention rate of 5.7. After implementation of different infection control measures included in their post-insertion bundle, the infection rates decreased markedly to 1.1. Our results in phase 2 were high compared to those of Guerin et al., which may be explained by defect in using complete protective barriers, also defect in applying aseptic techniques during insertion and maintenance of $\mathrm{CVC}$ related to proper hand hygiene. Also, several studies recorded nearly similar results to ours in phase 1 but their results were lower than our results after bundle implementation [31-33].

The overall compliance rate of the respondents in this study was $(69 \%)$ which was lower than the compliance in Miller's study which was ( $84 \%$ for insertion-bundle and $82 \%$ for maintenance-bundle). During their study, they formed collaborative teams responsible for training of health care workers (HCWs) and for bundles implementation [34]. Controversy, comparing our results to that reported by Sahli et al., 2017 in Algeria [35], it was found that in our study there was higher compliance concerning hand hygiene (92\%), skin antisepsis prior to CVC insertion $(100 \%)$ and barrier precautions application $(73 \%)$.

Not surprising that the rate of infection decreased to its minimal rates (1.6/ 1000 catheter days) in the last month of phase 2 in the present study, a finding that could be attributed to increased awareness of HCWs together with increased compliance to the bundle elements. Our reports showed that the rates of infection had declined more in each month with more compliance. Auditing in phase 2 played an important role in increasing the compliance. Continuous staff education, training on insertion and maintenance of $\mathrm{CVC}$, and regular auditing are very important and highly recommended.

Regarding the isolated microorganisms, Staphylococcus aureus was the most commonly isolated organisms (35.1\%) in our study followed by Coagulase negative Staphylococci (29.7\%). This result was in parallel with the results of several studies [36-40]. In the present study, Gram-negative micro-organisms played an important role in CLABSIs in which Pseudomonas aeruginosa caused $18.9 \%$ of infections followed by Klebsiella pneumonia (10.9\%), Enterobacter cloacae (2.7\%) and Acinetobacter baumannii (2.7\%). This should be taken into consideration for the empirical treatment of CLABSIs.

\section{Conclusions}

We could conclude that strict adherence to the bundle elements together with periodic surveillance; recording the infection rates and comparing with that of others will make a change.

\section{Funding}

No funding sources.

\section{Competing Interest}

None declared.

\section{Authors' Contributions}

Marwa Mostafa Shalaby designed the study, analyzed, interpreted the data and performed the statistical analysis. Kareman Ahmed Eshra, Radwa Abd El moteleb Essa and Ghada Mahmoud Alghazaly collected and analyzed the data. All the authors carefully revised the article and gave final approval of the article.

\section{REFERENCES}

[1] Eckardt KU, Barthlein B, Baid-Agrawal S, Beck A, Busch $\mathrm{M}$, et al. The German Chronic Kidney Disease (GCKD) study: design and methods. Nephrol Dial transplant; 27: 145 - 1460. 2012.

[2] Brenner and Rector. The kidney. Seventh edition. Philadelphia: Saunders; vol. 2: 2565-2614. 2004.

[3] Chan M R. Hemodialysis central venous catheter 
dysfunction. Semin Dial. ; 13:516-521. 2008.

[4] Xue Hui, Ix JH, Wang W, Brunelli SM, Lazarus M, et al. Hemodialsis Access Usage Patterns in the Incident Dialysis Year and Associated Catheter-Related Complications. Am J Kidney Dis; 61: 123 - 130. 2012.

[5] Santoro D, Benedetto F, Mondello P, et al. Vascular access for hemodialysis: current perspectives. Int. J. Nephrol. Renovasc. Dis.; 7: 281-294. 2014.

[6] Dhingra RK, Young EW, Hulbert-Shearon TE, Leavey SF, Port FK. Type of vascular access and mortality in US hemodialysis patients. Kidney Int.; 60(4):1443-1451. 2001.

[7] Miller L M, Clark E, Dipchand C, Hiremath S, Kappe J, et al. Hemodialysis Tunneled Catheter-Related Infections. Can J Kidney Health Dis; 3: p.1- 11. 2016.

[8] Mermel LA. Prevention of intravascular catheter-related infections. Ann Intern Med; 132 : 391 - 402. 2000.

[9] Subha Rao S, Joseph M, Lavi R and Macaden R. Infections related to vascular catheters in pediatric intensive care unit. Indian Pediatr; 42 : 667 - 672. 2005.

[10] Crnich CJ and Maki DG. The promise of novel technology for the prevention of intravascular device-related bloodstream infection. I. Pathogenesis and short-term devices. Clin Infect Dis.; 34(9): 1232-1242. 2002.

[11] Saxena AK and Panhotra BR. Haemodialysis catheter-related bloodstream infections: current treatment options and strategies for prevention. Swiss Med Wkly; 135 (9 - 10): 127 - 38. 2005.

[12] Mermel LA, Allon M, Bouza E, Craven DE, Flynn P et al. Clinical practice guide lines for diagnosis and management of intravascular catheter related infection. Clin Infect Dis; 49 (1): 1 - 45. 2009.

[13] Grayson ML. The treatment triangle for staphylococcus infections. N Engle J Med; 355 (7): 72 - 7. 2006.

[14] Deshpande LM, Fritsch TR, Moet GJ, Biedenbach DJ and Jones RN. Antimicrobial resistance and epidemiology of vancomycin resistant enterococci from North America and Europe: a report from the SENTRY antimicrobial surveillance program. Digan Microbiol Infect Dis; 58 (2): 163 - 70. 2007.

[15] Fram D, Castrucci FM, Taminato M, Gody-Martinez P, Freitas MC, Belasco A et al. Cross-transmission of vancomycin-resistant Enterococcus in patients undergoing dialysis and kidney transplant. Braz J Med Biol Res; 43 (1): $115-9.2010$.

[16] Grundmann H, Aanensen DM, van den Wijngaard CC, Spratt BG, Harmsen D et al. Geographic distribution of Staphylococcus aureus causing invasive infections in Europe : a molecular epidemiological analysis. PLoS Med; 7: $215-221.2010$.

[17] O'Grady N P, Alexander M., Burns L A., Dellinger E P, Garland, J., Heard, SO., Maki D G, et al. Guidelines for the Prevention of Intravascular Catheter-related Infections. Clin. Infect. Dis.; 52(9): e162-e193. 2011.

[18] Labeau SO, Vandijck DM, Rello J ,Adam S, Rosa A et al. Centers for disease control and prevention guide lines for preventing central venous catheter related infection. Crit
Care Med; 37: 320 - 323. 2009.

[19] Strasheim W, Kock MM, Ueckermann V, Hoosien E, Dreyer AW et al. Surveillance of catheter related infections: the supplementary role of the microbiology laboratory. BMC Infectious Diseases; 15: 5. 2015.

[20] Quittnat Pelletier F, Joarder M, Poutanen SM, and Lok CE. Evaluating Approaches for the Diagnosis of Hemodialysis Catheter-Related Bloodstream Infections. Clin J Am Soc Nephrol.; 11(5):847-854. 2016.

[21] Maki, D.G., Weise, C.E., Sarafin, H.W. A semiquantitative culture method for identifying intravenous catheter related infection. N. Eng. J. Med.: 296 (23): 1305-1309. 1977.

[22] Centers for Disease Control and Prevention (CDC) (2017). Blood stream Infection Event (Central Line-Associated Bloodstream Infection and non-central line-associated Bloodstream Infection). Retrieved from https://www.cdc.gov/nhsn/pdfs/pscmanual/4psc_clabscurre nt.pdf

[23] Yaseen M, Al- Hameed F, Osman K, et al. A project to reduce the rate of central line associated bloodstream infection in ICU patients to a target of zero. BMJ Quality Improvement Reports; 5: u212545. w4986. 2016.

[24] Rosenthal VD, Maki DG, Rodrigues C, Alvarez-Moreno C, Leblebicioglu $\mathrm{H}$, Sobreyra-Oropeza $\mathrm{M}$, et al. International Nosocomial Infection Control Consortium Investigators: Impact of international nosocomial infection control consortium (INICC) strategy on central line-associated bloodstream infection rates in the intensive care units of 15 developing countires. Infect Control Hosp Epidemiol., 31: 1264-1272. 2010

[25] Rosenthal VD, Ramachandran B, Villamil-Gómez W, Armas-Ruiz A, Navoa-Ng JA, Matta-Cortés L, et al. Impact of a multidimensional infection control strategy on central line-associated bloodstream infection rates in pediatric intensive care units of five developing countries: findings of the international nosocomial infection control consortium (INICC). Infect., 40: 415-423. 2012.

[26] García-Rodríguez JF, Alvarez-Díaz H, Vilariño-Maneiro L, Lorenzo-García MV, Cantón-Blanco A, Ordoñez-Barrosa P, et al. Epidemiology and impact of a multifaceted approach in controlling central venous catheter associated blood stream infections outside the intensive care unit. BMC Infect Dis., 13: 445.2013

[27] Rinke ML, Chen AR, Bundy DG, Colantuoni E, Fratino L, Drucis $\mathrm{KM}$, et al. Implementation of a central line maintenance care bundle in hospitalized pediatric oncology patients. Pediatrics., 130: e996-e1004. 2012.

[28] Dogru A, Sargin F, Celik M, Sagiroglu AE, Goksel MM, Sayhan H. The rate of device-associated nosocomial infections in a medical surgical intensive care unit of a training and research hospital in Turkey: one-year outcomes. Jpn J Infect Dis., 63: 95-98. 2010.

[29] Rosenthal VD, Guzman S, Pezzotto SM, Crnich CJ. Effect of an infection control program using education and performance feedback on rates of intravascular device-associated bloodstream infections in intensive care units in Argentina. Am J Infect Control., 31: 405-409. 2003.

[30] Higuera F, Rosenthal VD, Duarte P, Ruiz J, Franco G, 
Safdar N: The effect of process control on the incidence of central venous catheter-associated bloodstream infections and mortality in intensive care units in Mexico. Crit Care Med., 33: 2022-2027. 2005.

[31] Guerin K, Wagner, Rains, Bessesen. Reduction in central line-associated bloodstream infections by implementation of a postinsertion care bundle." American journal of infection control; 38(6): 430-433. 2010.

[32] Galpern, David, et al. Effectiveness of a central line bundle campaign on line-associated infections in the intensive care unit. Surgery ; 144 (4): 492-495. 2008.

[33] Miller, Marlene R., et al. "Decreasing PICU catheter-associated bloodstream infections: NACHRI's quality transformation efforts." Pediatrics; 125(2): 206-213. 2010 .

[34] Sacks, Greg D., et al. "Reducing the rate of catheter-associated bloodstream infections in a surgical intensive care unit using the Institute for Healthcare Improvement Central Line Bundle." Am. J. Surgery; 207(6): 817-823. 2014.

[35] Sahli F, Feidje R, and Laalaoui R. "Hemodialysis catheter-related infection: rates, risk factors and pathogens." J Infect Public Health; 10(4): 403-408. 2017.

[36] Saeed Abdulrahman I, Al-Mueilo SH, Bokhary HA, LadipoGO, and Al-Rubaish A. A prospective study of hemodialysis access related bacterial infections. J Infect Chemother; 8:242-6. 2002.

[37] Nabi Z, Anwar S, Barhamein M, Al Mukdad H, and El Nassri A.Catheter related infection in hemodialysis patients. Saudi J Kidney Dis Transpl; 20(6):1091—5. 2009.

[38] Lemaire X, Morena M, Leray-Moragues H, Henriet-Viprey D,Chenine L, Defez- Fougeron C, et al. Analysis of risk factors for catheter-related bacteremia in 2000 permanent dual catheters for hemodialysis. Blood Purif; 28: 21-8. 2009.

[39] Sanavi S, Ghods A, and Afshar R. Catheter associated infections in hemodialysis patients Saudi. J Kidney Dis Transpl; 18(1):43-6. 2007.

[40] Tanriover B, Carlton D, Saddekni S, Hamrick K, Oser R, West-fall AO, et al. Bacteremia associated with tunneled dialysis catheters: comparison of two treatment strategies. Kidney Int; 57:2151—5. 2000. 